\title{
Giant paraesophageal hernia repair: Technical pearls
}

\author{
Mara B. Antonoff, MD, Jonathan D'Cunha, MD, PhD, Rafael S. Andrade, MD, and \\ Michael A. Maddaus, MD
}

\begin{abstract}
The optimal operative management of giant paraesophageal hiatal hernias continues to evolve, with recent series reporting promising results with minimally invasive approaches. The laparoscopic repair of a giant paraesophageal hernia is one of the more challenging cases a minimally invasive surgeon may perform. Our technical approach to this procedure involves a consistent emphasis on several key operative points: circumferential sac dissection with maintenance of crural integrity; extensive mediastinal esophageal dissection; crural closure with pledgeted sutures; wedge Collis gastroplasty for shortened esophagus; 3 -stitch fundoplication incorporating esophageal tissue with each bite; additional sutures securing the top of the fundoplication to the crura; and biologic mesh buttressing. We believe that diligence paid toward these key steps permits laparoscopic giant paraesophageal hiatal hernia repair to be performed with similar outcomes as the open approach while avoiding the morbidity of thoracotomy or laparotomy. (J Thorac Cardiovasc Surg 2012;144:S67-70)
\end{abstract}

Giant paraesophageal hiatal hernia is a diagnosis for which, in a symptomatic patient, the definitive management is generally surgical repair. Previously, repair involved left thoracotomy, a Belsey or Nissen fundoplication, and frequent Collis gastroplasty. These approaches set the benchmarks for the outcomes of surgical repair against which surgeons have measured more recently reported series of laparoscopically performed procedures. When initial reports of laparoscopic repair were assessed, inconsistent and, in some cases, alarming short-term outcomes, raised significant concerns regarding the laparoscopic minimally invasive approach. In general, the more traditional thoracotomy approach resulted in complication rates ranging from $19 \%$ to $22 \%{ }^{1,2}$ and with low rates of recurrence $^{1,5}(\leq 7 \%)$ during intermediate follow-up periods.

Early follow-up of some of the initially reported series of laparoscopic repairs demonstrated unacceptably high early recurrence rates, up to $42 \%{ }^{3,4}$ A number of reasons could have contributed to these high rates, including injuring or tearing the crura (leaving only muscle on which to sew), poor sac dissection, and limited laparoscopic surgical skills. However, 2 particular features of the thoracotomybased repair that might have contributed to the success of the open procedure were the clear identification of the esophagogastric junction (EGJ), and, if a short esophagus was present $(<2.5 \mathrm{~cm})$, performance of an esophageal lengthening procedure, consisting of either the classic Collis gastroplasty ${ }^{1}$ or extensive total intrathoracic esophageal

From the Division of Thoracic and Foregut Surgery, Department of Surgery, University of Minnesota, Minneapolis, Minn.

Disclosures: Authors have nothing to disclose with regard to commercial support.

Presented at the 3rd International Minimally Invasive Thoracic Surgery Summit,

Boston, Massachusetts, October 7-8, 2011.

Received for publication Oct 31, 2011; accepted for publication March 22, 2012.

Address for reprints: Michael A. Maddaus, MD, Division of Thoracic and Foregut

Surgery, Department of Surgery, University of Minnesota, MMC 207, 420

Delaware St Southeast, Minneapolis, MN 55455 (E-mail: madda001@umn.edu). $0022-5223 / \$ 36.00$

Copyright (C) 2012 Published by Elsevier Inc. on behalf of The American Association for Thoracic Surgery

doi:10.1016/j.jtcvs.2012.03.065 mobilization, with particular attention paid to division of the branches of the vagal nerve to the left pulmonary hilum, releasing this area of the esophagus from tethering. ${ }^{5}$

Because of the technical challenges associated with performance of laparoscopic Collis gastroplasty, this component of the procedure was rarely, if ever, performed in the early series of minimally invasive repairs. This represented a major deviation from the standard of care, as delineated by Maziak and colleagues ${ }^{1}$ and Altorki and colleagues, ${ }^{5}$ of first clearly identifying the EGJ accurately and, if a short esophagus was present, lengthening the esophagus through either a Collis gastroplasty or extensive esophageal mobilization. Given the limited access to the upper one half or more of the esophagus using laparoscopy, the only viable option for performing esophageal lengthening laparoscopically was a Collis gastroplasty.

Through the continued efforts of Luketich and colleagues $^{6}$ at the University of Pittsburgh, progress was made in developing techniques to laparoscopically identify the EGJ accurately and reliably perform laparoscopic Collis gastroplasty. Initially, Luketich and colleagues ${ }^{6}$ reported successful performance of Collis gastroplasties using endto-end (EEA) staplers by way of a technically complicated practice. However, over time, the wedge Collis gastroplasty, as developed by Champion, ${ }^{7}$ became, in most centers, the standard method used, owing to its simplicity and reliability.

In our evolution of the operative management of giant hiatal hernias over a number of years, we have identified several technical principles to which we adhere in every operation. These technical principles are intended, as much as possible, to directly replicate the principles used in open procedures. Regardless of the approach, if these key principles are followed, in our experience, the operation will have a greater likelihood of success.

\section{TECHNICAL PEARL 1}

Our technical approach to giant hiatal hernia repair requires consistent emphasis on several key operative points ${ }^{8}$ (Figures 1 and 2). The stomach is left alone, and no attempt 


\section{Abbreviation and Acronym \\ EGJ = esophagogastric junction}

to reduce it is made, owing to the increased risk of gastric injury during such surgical "wrestling matches." Instead, the apex of the hernia sac is grasped vigorously and inverted by pulling caudally, and the sac is then opened well away from the crural edge. The dissection is then carried into the mediastinal areolar tissue plane, which is easy to free, and, after this procedure, the stomach essentially drops back into the abdomen. It cannot be overemphasized that there must be a wide margin between the crura and the sac incision in order to preserve an adequate margin of tissue for covering the crura (Figure 2, A).

\section{TECHNICAL PEARL 2}

Maintenance of crural integrity is emphasized as a fundamental objective. ${ }^{8}$ This entails avoidance of stripping the peritoneum and other connective tissues from the surface of the crural muscles. After division of the sac, the tissue overlying the crura should appear as a smooth and glistening surface without exposed muscle fibers. After sac division, the fat pad is dissected circumferentially, with care taken to stay just on the surface of the muscle fibers of the stomach and esophagus. By hugging the esophagus and stomach closely, the vagal nerves should be successfully preserved, because, in essence, one has performed a highly selective vagotomy over the area of the EGJ.

\section{TECHNICAL PEARL 3}

The crura are then closed in an interrupted fashion, using polytetrafluoroethylene pledgets for a reinforced repair, until they are closed approximately two thirds of the way from anteriorly to posteriorly (Figure 2, C and $D)$. The closure is performed using No. 1 Ethibond (Ethicon, Cincinnati, Ohio) suture on CT needles with intracorporeal knot tying. The use of standard suture and needles allows for appropriately sized, full-thickness crural bites, replicating the same closure that would be obtained during an open operation. ${ }^{8}$

\section{TECHNICAL PEARL 4}

The esophagus is then assessed for adequate length. If it is found to be short (ie, $<2.5 \mathrm{~cm}$ ), we perform a wedge Collis gastroplasty over a $46 \mathrm{~F}$ bougie (Figure $2, E$ ). The gastroplasty is begun with a blue stapler load brought in from the left upper quadrant port. With the greater curve of the stomach held anteriorly and inferiorly, the stapler can be brought in nearly perpendicular to the direction of the bougie. With closure of the stapler, the device can be felt to "pop" over the edge of the bougie. Typically, 1 additional stapler load is
- Invert sac and open into areolar plane of mediastinum

- Dissect sac circumferentially, leaving a wide margin to cover the crura

- Dissect fat pad circumferentially, preserving vagus nerves

- Close crura using pledgets

- After closing 2/3 of way posteriorly, assess esophageal length

- If esophagus $<2.5 \mathrm{~cm}$, perform Collis gastroplasty over $46 \mathrm{Fr}$ bougie

- Finish crural closure

- Perform 3-stitch fundoplication, catching part of esophagus with each stitch, over $56 \mathrm{Fr}$ bougie

- Suture top of fundoplication to crura

- Remove bougie, assess floppiness and configuration of crura

\section{- Biologic mesh placement}

FIGURE 1. Operative technique. Our technical approach to giant hiatal hernia repair requires consistent emphasis on several key operative points as shown.

necessary from this angle. Next, the final 1 or 2 staple loads are brought in from the right paramedian port, and, by firmly pressing the stapler atop the esophagus and bougie, one can be certain that the gastroplasty will be a straight channel with little or no excess capaciousness.

\section{TECHNICAL PEARL 5}

A fundoplication is next performed over a $56 \mathrm{~F}$ bougie. Remarkably, even if a 46F bougie is used for gastroplasty, a $56 \mathrm{~F}$ bougie can be subsequently inserted carefully without injury. The Nissen fundoplication is constructed with 3 stitches of 2-0 silk, with each stitch incorporating a moderate bite of esophageal musculature (Figure 2, $F$ and $G$ ). The critical point is to ensure that the fundus is wrapped around the esophagus snugly but not overly so. By holding the tip of the fundus in the surgeon's left hand and bringing the greater curve over to the tip of the fundus, one can judge the tightness of the wrap around the esophagus. The main error at this point is to have the wrap be too loose, leading to ineffective fundoplication. If the wrap is too tight, when the bougie is removed, one can identify this problem, because the fundus will appear as though it is under tension relative to the greater curve, as if the 2 structures were trying to pull apart. Also, with a properly constructed wrap, after removal of the bougie, the greater curve edge of the wrap should be able to 

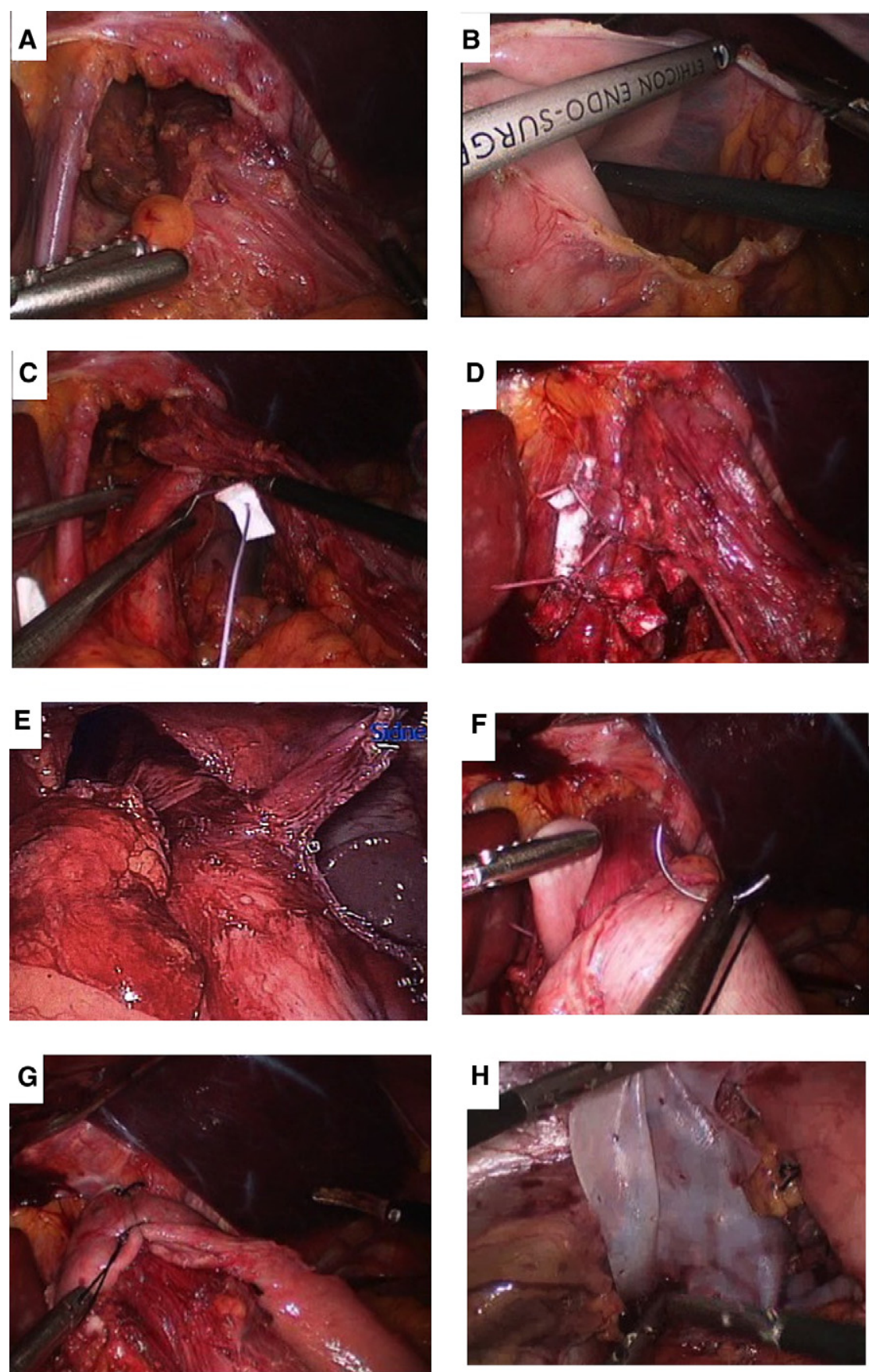

FIGURE 2. Key operative steps. A, Crural dissection; (B), taking down the short gastric vessels; (C), crural closure; (D), complete crural closure; (E), wedge gastroplasty; (F), start of wrap; (G), completed wrap; and (H), biologic mesh placement.

be lifted up, allowing room for a grasper to be easily inserted between the stomach and esophagus. Finally, after wrap construction, to anchor the wrap to the crura, 3 stitches of 2-0 silk are used to sew the top of the fundus to the crura.

\section{TECHNICAL PEARL 6}

The repair is completed with a biologic mesh buttressing (Surgisis; Cook, Bloomington, Ind) of the closed hiatal defect in the vast majority of cases, because multiple studies have suggested a lower recurrence rate with the use of this mesh. A simple square is cut, placed over the crural closure, and secured in place with absorbable tacks (Figure 2, $H$ ).

\section{DISCUSSION}

In consistently using the operative approach we have described, placing emphasis on the same key principles of the 
operation every time, we have achieved highly successful results, with competitive outcomes. ${ }^{9}$ Other investigators placing emphasis on similar key steps have been equally successful in treating giant hiatal hernias using a minimally invasive approach. ${ }^{10}$

In our practice, we are proponents of the use of biologic mesh to reinforce the hernia closure. The use of synthetic mesh has been described as a useful adjunct in the setting of hiatal hernia, reducing the recurrence risk from $6.1 \%$ to $0.6 \% .{ }^{11}$ Created from xenogenic or allogenic extracellular protein matrices, these mesh materials provide a bioscaffolding, serving as a lattice for revascularization and native cell integration. ${ }^{12}$ These compounds might consequently be less susceptible to erosion and infection.

A randomized, prospective, multicenter trial evaluating biologic mesh vs simple closure found that mesh reduced the 6-month risk of recurrence from $24 \%$ to $9 \%(P=$ $.04)$, without any mesh-related complications or side effects. ${ }^{13}$ A second phase of this trial aimed to determine long-term durability of the biologic mesh-buttressed repair, as determined radiologically. The benefit of biologic mesh in reducing hernia recurrence seems to be greatest in the early postoperative period, because the advantage dissipated somewhat with longer term follow-up. ${ }^{14}$

Despite early tribulations in the attempts to perform minimally invasive repair of giant paraesophageal hiatal hernias, recent reports from centers of excellence have demonstrated that such procedures can be performed safely and with promising results. ${ }^{8-10}$ In a review of outcomes from 662 patients who underwent laparoscopic giant paraesophageal hiatal hernia repairs, Luketich and colleagues ${ }^{10}$ reported excellent results during a 10 -year experience. The outcomes from this group revealed relatively short postoperative hospitalizations (3 days), low 30-day mortality $(1.7 \%)$, and readmission rates similar to those of other series $(7.5 \%)$. During follow-up, the patients were screened with esophagrams to assess for anatomic hiatal hernia recurrence. Although 15.7\% demonstrated recurrence on imaging, only $3.2 \%$ of this subgroup experienced symptom recurrence. Those with symptomatic recurrence were offered reoperation, at a rate comparable to that of the best open series. Importantly, $90 \%$ of patients reported good to excellent scores on evaluation of their symptomatic outcomes. These were assessed with a validated instrument, the Gastroesophageal Reflux Disease HealthRelated Quality of Life questionnaire, rendering their operations highly successful.

At the University of Minnesota, we have performed 394 giant hiatal hernia repairs since 2005. Our median hospital stay for this procedure has been 4 days, with a low morbidity rate of only $8.2 \% .{ }^{9}$ Using postoperative radiographic imaging for anatomic follow-up, we have found a $5.5 \%$ recurrence rate, with reoperation needed for only $1.3 \%$. More than $90 \%$ of our patients have achieved good or excellent results as assessed using the Gastroesophageal Reflux Disease Health-Related Quality of Life questionnaire. We attribute our high rate of successful symptom resolution and rare hernia recurrence to our consistent emphasis on the key operative principles in the minimally invasive approach, aimed at adherence to the fundamentals of open repair. ${ }^{9}$

The benefits afforded our patients by access to minimally invasive operative procedures are numerous. This holds true, however, only if our minimally invasive operations are held to the same standards of safety and quality as the traditional open procedures. This ideal has been effectively demonstrated in recent series of giant paraesophageal hiatal hernia repairs at centers of excellence, with the understanding that the key operative principles must hold, regardless of whether the approach is open or laparoscopic.

\section{References}

1. Maziak DE, Todd TR, Pearson FG. Massive hiatus hernia: evaluation and surgical management. J Thorac Cardiovasc Surg. 1998;115:53-61, 52.

2. Patel HJ, Tan BB, Yee J, Orringer MB, Iannettoni MD. A 25-year experience with open primary transthoracic repair of paraesophageal hiatal hernia. J Thorac Cardiovasc Surg. 2004;127:843-9.

3. Dahlberg PS, Deschamps C, Miller DL, Allen MS, Nichols FC, Pairolero PC. Laparoscopic repair of large paraesophageal hiatal hernia. Ann Thorac Surg. 2001;72:1125-9.

4. Hashemi M, Peters JH, DeMeester TR, et al. Laparoscopic repair of large type III hiatal hernia: objective followup reveals high recurrence rate. ACS. 2000;190: 553-60, 551 .

5. Altorki NK, Yankelevitz D, Skinner DB. Massive hiatal hernias: the anatomic basis of repair. J Thorac Cardiovasc Surg. 1998;115:828-35.

6. Luketich JD, Raja S, Fernando HC, et al. Laparoscopic repair of giant paraesophageal hernia: 100 consecutive cases. Ann Surg. 2000;232:608-18.

7. Champion JK. Laparoscopic vertical banded gastroplasty with wedge resection of gastric fundus. Obes Surg. 2003;13:465.

8. D'Cunha J, Andrade RS, Maddaus MA. Surgical management of gastroesophageal reflux disease/Barrett's esophagus. Minerva Chir. 2011;66:7-19.

9. Whitson BA, Hoang CD, Boettcher AK, Dahlberg PS, Andrade RS, Maddaus MA. Wedge gastroplasty and reinforced crural repair: important components of laparoscopic giant or recurrent hiatal hernia repair. J Thorac Cardiovasc Surg. 2006;132:1196-1202.e1193.

10. Luketich JD, Nason KS, Christie NA, et al. Outcomes after a decade of laparoscopic giant paraesophageal hernia repair. J Thorac Cardiovasc Surg. 2010; 139:395-404, 404.e391.

11. Granderath FA, Schweiger UM, Kamolz T, Pasiut M, Haas CF, Pointner R. Laparoscopic antireflux surgery with routine mesh-hiatoplasty in the treatment of gastroesophageal reflux disease. J Gastrointest Surg. 2002;6:347-53.

12. Badylak SF. Xenogeneic extracellular matrix as a scaffold for tissue reconstruction. Transplant Immunol. 2004;12:367-77.

13. Oelschlager BK, Pellegrini CA, Hunter J, et al. Biologic prosthesis reduces recurrence after laparoscopic paraesophageal hernia repair: a multicenter, prospective, randomized trial. Ann Surg. 2006;244:481-90.

14. Oelschlager BK, Pellegrini CA, Hunter JG, et al. Biologic prosthesis to prevent recurrence after laparoscopic paraesophageal hernia repair: long-term follow-up from a multicenter, prospective, randomized trial. J Am Coll Surg. 2011;213:461-8. 